\title{
Proteomic Analysis to Identify Tightly-Bound Cell Wall Protein in Rice Calli
}

\author{
Won Kyong Cho ${ }^{1,5}$, Tae Kyung Hyun ${ }^{2,5}$, Dhinesh Kumar, ${ }^{1,5}$, Yeonggil Rim', Xiong Yan Chen', Yeonhwa Jo', \\ Suwha Kim ${ }^{3}$, Keun Woo Lee', Zee-Yong Park', William J. Lucas', and Jae-Yean Kim ${ }^{1, *}$
}

\begin{abstract}
Rice is a model plant widely used for basic and applied research programs. Plant cell wall proteins play key roles in a broad range of biological processes. However, presently, knowledge on the rice cell wall proteome is rudimentary in nature. In the present study, the tightly-bound cell wall proteome of rice callus cultured cells using sequential extraction protocols was developed using mass spectrometry and bioinformatics methods, leading to the identification of 1568 candidate proteins. Based on bioinformatics analyses, 389 classical rice cell wall proteins, possessing a signal peptide, and 334 putative non-classical cell wall proteins, lacking a signal peptide, were identified. By combining previously established rice cell wall protein databases with current data for the classical rice cell wall proteins, a comprehensive rice cell wall proteome, comprised of 496 proteins, was constructed. A comparative analysis of the rice and Arabidopsis cell wall proteomes revealed a high level of homology, suggesting a predominant conservation between monocot and eudicot cell wall proteins. This study importantly increased information on cell wall proteins, which serves for future functional analyses of these identified rice cell wall proteins.
\end{abstract}

\section{INTRODUCTION}

In higher plants, the cell wall, also known as the extracellular matrix, functions as a means of mechanical support as well as establishing an apoplasmic matrix for signaling and defense. The initial cell wall is deposited during cytokinesis and is termed the primary wall; it is composed of polysaccharides, such as

\begin{abstract}
${ }^{1}$ Division of Applied Life Science (BK21plus), Plant Molecular Biology and Biotechnology Research Center, Gyeongsang National University, Jinju 660-701, Korea, ${ }^{2}$ Department of Industrial Plant Science and Technology, College of Agricultural, Life and Environmental Sciences, Chungbuk National University, Cheongju 361-763, Korea, ${ }^{3}$ Department of Life Science, Gwangju Institute of Science and Technology, Gwangju 500-712, Korea, ${ }^{4}$ Department of Plant Biology, University of California, Davis, CA 95616, USA, ${ }^{5}$ These authors contributed equally to this work. *Correspondence: kimjy@gnu.ac.kr
\end{abstract}

Received 6 February, 2015; revised 29 May, 2015; accepted 1 June, 2015; published online 17 July, 2015

Keywords: callus, cell wall proteins, MudPIT, proteomics, rice cellulose, hemicelluloses, and pectins (Keegstra, 2010; Pettolino et al., 2012; Tan et al., 2013; Yang et al., 2011). In the case where wall strengthening is required, this is achieved through the formation of secondary walls and, here, lignin is also incorporated into the polysaccharide matrix. These wall constituents are thought to play important roles in wall maintenance, metabolic and developmental regulation, as well as responses to environmental cues (Jamet et al., 2008; Rose and Lee, 2010). As a prerequisite to developing a comprehensive understanding of the functional importance of cell wall proteins, it will be necessary to compile cell wall proteomes for a number of model plant species. To this end, cell wall proteomics studies have been performed on alfalfa, Arabidopsis, chickpea, maize, rice, soybean, tobacco, tomato, and wheat (Bayer et al., 2006; Bhushan et al., 2006; Chen et al., 2009; Cho et al., 2009; Dahal et al., 2010; Komatsu et al., 2010; Kong et al., 2010; Millar et al., 2009; Watson et al., 2004; Zhu et al., 2007). Of these plant species, the most extensive database has been developed for Arabidopsis; here, some 500 proteins have been identified using a combination of 2D-gel/MudPIT and genome/bioinformatics tools (Bayer et al., 2006; Borderies et al., 2003; Charmont et al., 2005; Chivasa et al., 2002; Ndimba et al., 2003).

To date, rice cell wall proteomics studies have focused on identifying non-bound apoplasmic and weakly-bound proteins, but not tightly-bound cell wall proteins. Other studies have investigated the induction of wall proteins in response to cold, dehydration, pathogen challenge and chemical stress (Chen et al., 2009; Cho et al., 2009; Cui et al., 2005; Ge et al., 2008; Jung et al., 2008; Kim et al., 2009; Pandey et al., 2010; Zhou et al., 2011). Previously, our group employed a rice callus culture system to identify non-redundant classical cell wall proteins containing conventional signal peptides. Here, 249 and 153 cell wall proteins were characterized as weakly-bound and secreted proteins, respectively (Chen et al., 2009; Cho et al., 2009). Given that the number of identified rice classical cell wall proteins was significantly below that observed for Arabidopsis, it would seem that this database is not yet comprehensive in nature.

Cell wall proteins have various affinities to the extracellular matrix, ranging from fully mobile proteins to those that are tightly integrated into the matrix, via covalent linkages; these latter proteins cannot be extracted by strong salt solutions (Jamet et al., 2008; Rose and Lee, 2010). Destructive methods, which require extensive grinding of the plant material, $\mathrm{CaCl}_{2}$ extraction and SDS/ dithiothreitol extraction, have previously been employed to extract tightly-bound cell wall proteins (Feiz et al., 
2006; Jamet et al., 2008; Rose and Lee, 2010). In the present study, an expanded rice cell wall proteome, based on callus cultured cells, was developed using mass spectrometry and bioinformatics methods. A combination of destructive and sequential extraction protocols was employed to purify tightlybound wall proteins; this approach led to the identification of 1,999 candidate proteins. Based on bioinformatics analyses, 389 classical rice cell wall proteins, possessing a signal peptide, and putative 334 non-classical cell wall proteins, lacking a signal peptide, were identified. The classical rice callus cell wall proteins were compared to previously established rice callus cell wall protein databases, and a comprehensive rice callus cell wall proteome containing 496 proteins was constructed. A comparative analysis of the rice and Arabidopsis cell wall proteomes revealed a high level of homology, suggesting a predominant conservation between monocot and eudicot cell wall proteins.

\section{MATERIALS AND METHODS}

\section{Callus induction}

Rice callus cultures were established using the following procedure. Rice seeds (Oryza sativa L. cv. 'Dongjin') were first dehusked and washed in tap water to remove dust and other surface contaminants. Washed seeds were then surfacesterilized for $30 \mathrm{~min}$ in $2 \% \mathrm{NaOCl}$ solution, rinsed extensively ( 3 times) with sterilized water and then inoculated on Nitsch's basal (NB) callus induction medium (N6 major salts, N6 minor salts, N6 vitamins, $1 \mathrm{~g} / \mathrm{L}$ casamino acids, $30 \mathrm{~g} / \mathrm{L}$ sucrose, 2 $\mathrm{mg} / \mathrm{L}$ 2,4-D, 2 g/L Gelrite, pH 5.8), as previously described (Hiei et al., 1994). Callus formation was induced by culturing seeds at $30^{\circ} \mathrm{C}$ in darkness for three weeks. Proliferating calli were sub-cultured on NB medium every two weeks.

\section{Isolation of cell walls from rice calli}

Aliquots $(20 \mathrm{~g})$ of cultured rice calli (Fig. 1A) were first frozen in liquid nitrogen and cells were then disrupted using several rounds of vortexing in a commercial blender that was prechilled. Disrupted rice calli were further homogenized using a mortar and pestle. Wall preparation buffer (WPB; $50 \mathrm{mM}$ Tris, $\mathrm{pH}$ 8.0, $100 \mathrm{mM} \mathrm{KCl}, 10 \% \mathrm{v} / \mathrm{v}$ glycerol, $10 \mathrm{mM}$ EDTA, $1 \mathrm{mM}$ DTT and $1 \mathrm{mM}$ phenylmethanesulfonylfluoride [PMSF]) was added to homogenized calli ( $4 \mathrm{ml} / \mathrm{g}$ of wall preparation) and the mixture was then centrifuged, at $400 \times \mathrm{g}$, for 5 min using a 5810 $R$ centrifuge (Eppendorf AG, Germany). The supernatant was discarded and the pellet (Fig. 1B) was resuspended in $400 \mathrm{ml}$ WPB, without PMSF. This suspension was then further homogenized using three rounds of French press treatment (13 MPa minimal outlet aperture pressure). Next, $200 \mathrm{ml}$ of WPB was added, followed by sonication ( $1 \mathrm{~min} \times 10$ cycles). Aliquots of the suspended pellet (Fig.1C) were equally distributed into four $250 \mathrm{ml}$ tubes. Each tube was centrifuged at $428 \times \mathrm{g}$ for $3 \mathrm{~min}$, the pellet was then washed with $50 \mathrm{ml}$ of WPB containing $0.1 \%$ triton X-100 and recentrifuged at $260 \mathrm{x} \mathrm{g}$ for $3 \mathrm{~min}$; this step was repeated twice, followed by centrifugation at $115 \times \mathrm{g}$ for $3 \mathrm{~min}$. After each centrifugation, the supernatant was removed. Finally, the pellet was washed five times with $50 \mathrm{ml}$ of WPB without triton $\mathrm{X}-100$ and then centrifuged at $115 \times \mathrm{g}$ for $3 \mathrm{~min}$, yielding a clear supernatant.

\section{Protein extraction from rice cell walls}

To extract proteins from purified rice callus cell walls, two volumes of $0.2 \mathrm{M} \mathrm{CaCl}_{2}$ solution were added to the final cell wall pellet and the mixture was incubated for $2 \mathrm{~h}$ with stirring at $4^{\circ} \mathrm{C}$.

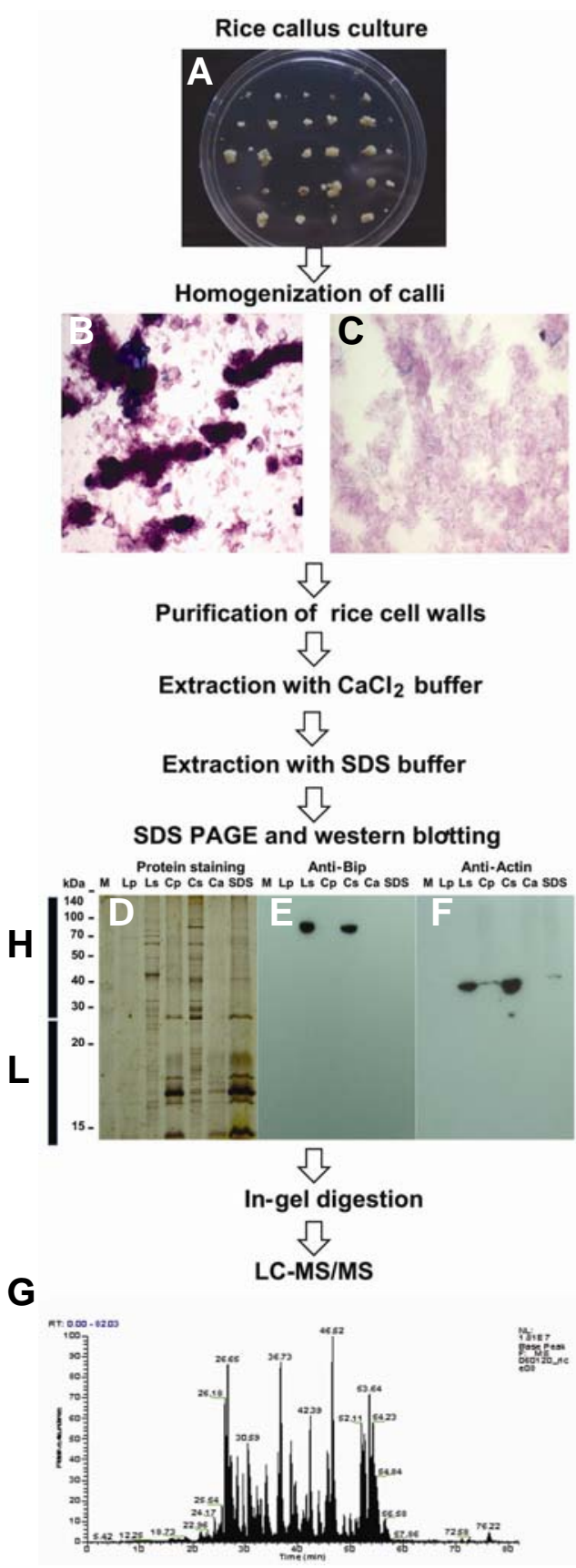

Fig. 1. Experimental scheme for extraction of tightly-bound rice cell wall proteins. (A) Rice callus culture was maintained on NB medium. (B) Rice calli after homogenization in a blender, followed by grinding using a mortar and pestle; note the presence of remaining intact tissue. (C) Complete cellular disruption achieved following French press treatment. (D) Extracted cell wall proteins separated on 1-D SDS-PAGE: M, molecular marker; Lp, leaf pellet; Ls, leaf soluble fraction; $\mathrm{Cp}$, callus pellet; $\mathrm{Cs}$, callus soluble fraction (cytosolic proteins in supernatant); $\mathrm{Ca}, \mathrm{CaCl}_{2}$-extracted cell wall proteins derived from Cp; SDS, SDS-extracted proteins from pellet after $\mathrm{CaCl}_{2}$ extraction. (E, F) Western blot analyses performed to evaluate the purity of extracted cell wall proteins. Actin (E): cytosolic and PD marker, BiP (F): ER marker. (G) An MS/MS spectrum conducted to identify rice cell wall proteins. 
After centrifugation at $15000 \times \mathrm{g}$ for $3 \mathrm{~min}$, the supernatant was collected and extracted proteins were incubated with four volumes of cold acetone for $2 \mathrm{~h}$ at $4^{\circ} \mathrm{C}$. The mixture was centrifuged at $15000 \times \mathrm{g}$ for $15 \mathrm{~min}$, and the resultant pellet was dried and resuspended in a minimal volume of sample buffer. The remaining pellet was further sequentially washed with $0.2 \mathrm{M}$ $\mathrm{CaCl}_{2}$ solution and TBS buffer. Residual proteins were extracted from the pellet by boiling for $5 \mathrm{~min}$ in two volumes of $2 \mathrm{X}$ sodium dodecyl sulfate (SDS) extraction buffer $(62 \mathrm{mM}$ Tris- $\mathrm{HCl}$, $\mathrm{pH} 6.8,2 \%$ SDS, $10 \%$ v/v glycerol, $0.005 \%$ bromophenol blue, $100 \mathrm{mM}$ dithiothreitol).

\section{In-gel digestion and peptide sample preparation}

Extracted proteins were loaded onto a $12 \%$ polyacrylamide mini-gel $(5 \times 8 \mathrm{~cm})$ for 1 -D SDS-PAGE $(100 \mathrm{~V}$ for $45 \mathrm{~min}$ in SDS-PAGE running buffer; $25 \mathrm{mM}$ Tris, $\mathrm{pH}$ 8.3, $192 \mathrm{mM}$ glycine, $0.1 \%$ SDS). Analytical and preparative gels were visualized with silver-staining (Yan et al., 2000) and Coomassie brilliant blue (CBB) staining buffer (50\% methanol, $10 \%$ glacial acetic acid, $40 \% \mathrm{H}_{2} \mathrm{O}, 0.5 \mathrm{~g} / \mathrm{L} \mathrm{CBB}$ ), respectively. Gels were washed thoroughly with destaining buffer (30\% methanol, $10 \%$ glacial acetic acid in $\mathrm{H}_{2} \mathrm{O}$ ) and then cut into two parts to yield high and low molecular weight portions. These gel pieces were trypsindigested and processed for LC-MS/MS analysis.

\section{MudPIT analysis}

MudPIT analysis was conducted as described previously (Cho et al., 2009). In brief, peptides were pressure-loaded onto a fused silica capillary column $(100 \mu \mathrm{m}$ i.d.) that contained $7 \mathrm{~cm}$ of $5-\mu \mathrm{m}$ Aqua C18 material (Phenomenex, USA), $3 \mathrm{~cm}$ of $5 \mu \mathrm{m}$ Partisphere strong cation exchanger (Whatman, USA), and 3 $\mathrm{cm}$ of $5-\mu \mathrm{m}$ Aqua $\mathrm{C} 18$ reversed phase column material (Phenomenex). Peptides were eluted from the microcapillary column and electrosprayed into a LTQ linear ion trap mass spectrometer (ThermoElectron), with a $2.3-\mathrm{kV}$ spray voltage used distally and applied to the waste of the HPLC split. A cycle of a full-scan mass spectrum (400-1400 m/z) followed by nine data-dependent tandem mass spectrometry (MS/MS) spectra at $35 \%$ normalized collision energy was repeated continuously throughout the multidimensional separation. The MS/MS spectra obtained from the LC-ESI-MS/MS analyses were used to search against a rice protein database from the NCBI website (http://www.ncbi.nlm.nih.gov/) using TurboSequest (SageN, CA), while tandem mass spectra were extracted using BioWorks version 3.0. Charge state deconvolution and deisotoping were not carried out. Sequest was searched with a fragment ion mass tolerance of 1.0 Da and a parent ion tolerance of 3.0 Da. The iodoacetamide derivative of cysteine was allowed in Sequest as a fixed modification (cysteines +57 ). Oxidation of methionine was assigned in Sequest searches as a variable modification (methionine +16$)$, with a maximum of three modifications allowed per peptide (the maximum number of modification per type was five), and maximum of two missed cleavage sites for trypsin digestion. Proteins that contained similar peptides and could not be differentiated, based on MS/MS analysis alone, were grouped to satisfy the principles of parsimony. Bioworks v. 3.0 was used to filter the search results, and the following Xcorr values and a delta $\mathrm{Cn}$ value of 0.1 were applied to different charge states of peptides: 1.8 for singly charged peptides, 2.5 for doubly charged peptides, and 3.5 for triply charged peptides. A requirement of at least one tryptic-digested end was used in the filtering process.

Bioinformatics analyses

SignalP 3.0 program including two different algorithms (Signal-
NN and SignalP-HMM; http://www.cbs.dtu.dk/services/SignalP) was used to predict the presence and location of signal peptide cleavage sites in each identified protein sequence (Emanuelsson et al., 2007). The 0.43 value was applied as a default cutoff in both $\mathrm{NN}$ and $\mathrm{HMM}$ algorithms. If the score was higher than the selected cutoff, the comment would be 'Yes', otherwise the comment would be 'No'. To predict transmembrane domains, in each identified protein sequences, the TMHMM v. 2.0 program was applied (http://www.cbs.dtu.dk/services/TMHMM) (Möller et al., 2001). The cutoff value for the TMHMM program was 0.5 , indicating the presence of predicted transmembrane helices.

The TargetP 1.1 was used to predict proteins localized to plastids and mitochondria with appropriate default parameters (Emanuelsson et al., 2007). Non-classical secreted proteins were predicted by the SecretomeP program and proteins with a neural network-score (NN-score) more than 0.5 were considered as non-classical secreted proteins (Bendtsen et al., 2004). Three different web-based programs, PredGPI prediction server (http://gpcr2.biocomp.unibo.it/gpipe/index.htm), GPI-SOM (http:// gpi.unibe.ch/) and Big-PI Predictor (http://mendel.imp.ac.at/gpi/ gpi_server.html), were used to identify glycosylphosphatidylinositol (GPI) anchored signals (Eisenhaber et al., 2003; Fankhauser and Mäser, 2005; Pierleoni et al., 2008). In general proteins with GPI-anchoring signals should possess a signal peptide for the secretory pathway; therefore, proteins having both $\mathrm{N}$ - and C-terminal signals were regarded as GPI-anchored proteins by the GPI-SOM program. The specificity cutoff for the PreGPI program should be more than $99 \%$ and the Big-PI program produced the quality of the site with $\mathrm{P}$ or $\mathrm{S}$.

Conserved protein domains were identified by performing InterProScan (http://www.ebi.ac.uk/Tools/InterProScan) implemented in Blast2GO (Götz et al., 2008; Mulder and Apweiler, 2007). When a protein contained endoplasmic reticulum (ER) retention signals, like KDEL or HDEL sequences at the Cterminus, it was regarded as an ER protein (Denecke et al., 1992). To remove redundant rice proteins, all identified proteins were reassigned with corresponding rice accession numbers, using BLASTP (http://blast.ncbi.nlm.nih.gov/Blast.cgi) (Altschul et al., 1997). In order to find homologous Arabidopsis cell wall proteins, all rice proteins were blasted against the whole Arabidopsis proteome. For the BLASTP analysis, an E-value of $1 \mathrm{E}-6$ was used as a threshold.

\section{Immunoblot analyses}

To perform immunoblot analyses of the extracted proteins, two different antibodies were used. One was anti-actin known to detect proteins localized in the cytoplasm and plasmodesmata (PD). The second was anti-BiP, which detects the molecular chaperone, $\mathrm{BiP}$, located in the ER lumen. Proteins were separated on $10 \%$ SDS-PAGE gels and electro-transferred onto PVDF membrane. After blocking with $7 \%$ skim milk, the membrane was incubated with rabbit polyclonal anti-actin (LabFrontier) or mouse monoclonal anti-BiP antibodies (Stressgen). Then horse radish peroxidase-conjugated donkey anti-rabbit, or goat anti-mouse, secondary antibodies (Santa Cruz Biotechnology) were used to react with anti-actin and anti-BiP, respectively. The antibodies were detected by chemiluminescence with an ECL kit (Amersham Biosciences).

\section{Cloning, agroinfiltration and confocal imaging}

To validate cell wall localization of non-classical secreted proteins, two candidate proteins, LOC_Os02g37710.1 and LOC Os01g71860.1, were selected. The respective full length CDS was amplified without its stop codon by PCR with gene specific 
Rice Cell Wall Proteome

Won Kyong Cho et al.

primers (LOC Os02g37710.1 FW [AAAAAGCAGGCTTTATGGAGCTCGTGGAGACAG], LOC_Os02g37710.1_RE [AGAAAGCTGGGTTCGGGCTAGTTCCGCTC], LOC_Os01g71860.1 FW [AAAAAGAGGCTTTATGGGAGCTGTCAATGGTGT] and LOC_Os01g71860.1_RE [AGAAAGCTGGGTTATTCGAAAAGGCAATCTGATAGAC]) containing attB gateway sites using cDNA prepared from rice seedlings. Purified PCR products were cloned into the pDONR207 entry vector by the BP reaction, according to the manufacturer's instructions (Invitrogen, Germany). LR clonase reactions were next performed to transfer each CDNA from the entry clone into a pMDC83 gateway compatible destination vector containing an N-terminal GFPhis 6 -tagged fusion driven by the $35 \mathrm{~S}$ promoter, according to the manufacturer's instructions (Invitrogen; Curtis and Grossniklaus, 2003). Purified plasmids were finally transformed into competent Agrobacterium strain GV3101 by electroporation.

Agrobacterium cells harboring each GFP fusion construct were grown to an OD600 of 1.0 in liquid yeast extract peptone (YEP) medium ( $1 \%$ peptone, $1 \%$ yeast extract, and $0.5 \% \mathrm{NaCl})$ supplemented with $50 \mu \mathrm{g} / \mathrm{ml}$ kanamycin, $50 \mu \mathrm{g} / \mathrm{ml}$ rifampicin and $25 \mu \mathrm{g} / \mathrm{ml}$ gentamicin overnight at $28^{\circ} \mathrm{C}$. Cells were pelleted, resuspended at $\mathrm{OD} 600=1.0$ in infiltration buffer $[10 \mathrm{mM} \mathrm{MgCl} 2$, $10 \mathrm{mM}$ MES (pH 5.6), $100 \mu \mathrm{M}$ acetosyringone], incubated for 2-3 $\mathrm{h}$ at room temperature, and infiltrated into the abaxial side of 6-week-old Nicotiana benthamiana leaves using a 1-ml needleless syringe. Agrobacterium harboring the Tomato bushy stunt virus P19 silencing suppressor was also co-infiltrated in order to minimize the gene silencing effects on heterologous gene expression in tobacco.

After $36 \mathrm{~h}$ post-infiltration, green fluorescent signals were observed in leaves using an Olympus (Japan) confocal laser scanning microscope (model FV1000). Excitation and emission wavelengths for GFP were $488 / 510-540 \mathrm{~nm}$. To perform plasmolysis experiments, cut leaf sections from $N$. benthamiana leaves transiently expressing GFP fusion constructs were vacuum-infiltrated in $0.8 \mathrm{M}$ mannitol for $1 \mathrm{~h}$. After a short incubation period, GFP signals were observed using a CLSM.

\section{RESULTS}

Extraction and identification of rice callus cell wall proteins To extract tightly-bound cell wall proteins, two extraction buffers were sequentially employed. The highly purified cell wall fraction was first subjected to $0.2 \mathrm{M} \mathrm{CaCl}_{2}$ extraction solution that has been well characterized as an excellent agent to remove cell wall proteins (Kim et al., 2013; Robertson et al., 1997). Next, an SDS extraction buffer, including $100 \mathrm{mM}$ dithiothreitol, was used to remove residual tightly-bound cell wall proteins from the cell wall pellet. The $\mathrm{CaCl}_{2}$ and SDS extracted cell wall proteins, as well as cytosolic proteins, were loaded onto 1-D SDS-PAGE gels. These cell wall-extracted proteins displayed quite different profiles as compared to the cytosolic proteins (Fig. 1D). In both cell wall protein fractions extracted by the $\mathrm{CaCl}_{2}$ and SDS treatments, strong protein bands were detected predominantly in the low molecular weight regions below $20 \mathrm{kDa}$ (Fig. 1D). Note that the band intensity for cell wall proteins extracted with SDS was stronger than that for the $\mathrm{CaCl}_{2}$ treatment. Furthermore, a number of high molecular weight bands were present in the SDS extracted cell wall proteins (Fig. 1D), indicating that SDS/dithiothreitol-based extraction is much effective compared to $\mathrm{CaCl}_{2}$-based extraction.

To evaluate the purity of these cell wall-extracted proteins, western blot analysis was performed using antibodies specific for actin, a cytosolic/plasmodesmal marker, and BiP, an endo-

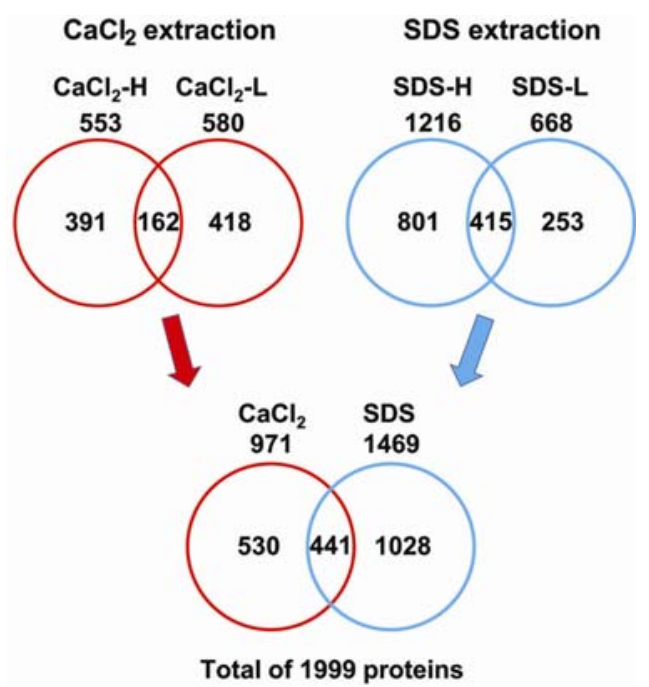

Fig. 2. Venn diagrams illustrating the populations of rice proteins identified using $\mathrm{CaCl}_{2}$ and SDS extraction methods. (A) $\mathrm{CaCl}_{2}-$ extracted proteins were separated and processed based on the scheme presented in Fig. 1. $\mathrm{CaCl}_{2}-\mathrm{H}$ and $\mathrm{CaCl}_{2}-\mathrm{L}$; total number of proteins identified within the high $(\mathrm{H})$ and low $(\mathrm{L})$ molecular weight fractions. (B) SDS-extracted proteins were separated and processed based on the scheme presented in Fig. 1. SDS-H and SDS$\mathrm{L}$; total number of proteins identified within the high $(\mathrm{H})$ and low $(\mathrm{L})$ molecular weight fractions. (C) Comparison between rice proteomes extracted by $\mathrm{CaCl}_{2}$ and SDS methods. A total of 1999 nonredundant rice callus proteins were identified using this sequential two-step extraction protocol.

plasmic reticulum (ER) lumen-localized soluble protein. Strong BiP signals were detected in only the leaf (Ls) and callus (Cs) soluble fractions (Fig. 1E), but not in pellet fractions ( $\mathrm{Lp}$ and $\mathrm{Cp}$ ). Actin was detected strongly in the leaf (Ls), callus (Cs) soluble fractions and weakly in callus pellet (Cp) (Fig. 1F). Furthermore, actin was also detected in the SDS-extracted cell wall fraction (Fig. 1F). These results are consistent with the hypothesis that the proteins contained within the $\mathrm{CaCl}_{2}$ and SDS extracted cell wall fractions are likely highly enriched with extracellular proteins. In this regard, actin detected in the SDS fraction may reflect protein derived from PD (Baluska et al., 2004). To prepare the isolated cell wall proteins for interrogation by mass spectrometry, samples were first separated on 1-D SDS-PAGE gels which were subsequently divided into high and low molecular weight sections (Fig. 1D). Following in-gel trypsin digestion, samples were analyzed by LC-MS/MS and protein identification achieved using a TurboSEQUEST program in conjunction with the rice protein database (Fig. 1G). Full details regarding peptide sequences are contained in Supplementary Tables S1-S4.

All identified rice proteins with GenBank identifier (GI) numbers were converted to the corresponding rice protein locus, based on the rice genome annotation (http://rice.plantbiology. msu.edu/) (Ouyang et al., 2007). After removal of redundant proteins, some 553 and 580 proteins were identified from the high and low molecular weight gel sections, respectively, based on the $\mathrm{CaCl}_{2}$ extraction protocol (Fig. 2A). Statistics for SDS extracted proteins were 1216 and 668 proteins contained within the high and low molecular weight gel fractions, respectively (Fig. 2B). More proteins (1469 in total) were contained 
Table 1. Representative rice classical cell wall proteins containing signal peptides predicted by SignalP 3.0

\begin{tabular}{|c|c|c|c|c|c|}
\hline $\mathrm{Gl}^{\mathrm{a}}$ & Function & $\begin{array}{c}\text { Molecular } \\
\text { mass }\end{array}$ & $\mathrm{pl}$ & $\begin{array}{c}\text { Sequence } \\
\text { count }\end{array}$ & $\begin{array}{l}\text { Sequence } \\
\text { coverage }\end{array}$ \\
\hline 21104619 & Thaumatin family & 26189 & 7.7 & 104 & $92 \%$ \\
\hline 62733218 & Glycosyl hydrolase & 33947 & 9.3 & 64 & $79 \%$ \\
\hline 113683 & Alpha-amylase & 48708 & 5.6 & 62 & $73 \%$ \\
\hline 55168113 & Glycosyl hydrolase & 32549 & 6.5 & 59 & $70 \%$ \\
\hline 50918709 & Periplasmic beta-glucosidase & 67778 & 7.5 & 45 & $43 \%$ \\
\hline 34895554 & Glycosyl hydrolase family 31 & 102551 & 6.5 & 40 & $43 \%$ \\
\hline 50508397 & Glucan endo-1, 3-beta-glucosidase & 59363 & 5.4 & 33 & $64 \%$ \\
\hline 50940911 & Cysteine-rich repeat secretory protein 55 & 30046 & 7.9 & 33 & $67 \%$ \\
\hline 50905163 & Retrotransposon protein & 70761 & 7.7 & 28 & $35 \%$ \\
\hline 51963488 & Polygalacturonase inhibitor & 35465 & 7.4 & 28 & $76 \%$ \\
\hline 50940909 & Cysteine-rich repeat secretory protein 55 & 29829 & 7.9 & 26 & $62 \%$ \\
\hline 53792759 & Retrotransposon protein & 56264 & 7.9 & 23 & $41 \%$ \\
\hline 113682 & Alpha-amylase & 47911 & 6.4 & 23 & $59 \%$ \\
\hline 51964350 & Dehydrogenase & 42702 & 7.8 & 21 & $55 \%$ \\
\hline 50940901 & Cysteine-rich repeat secretory protein 55 & 29695 & 7.9 & 21 & $57 \%$ \\
\hline 113766 & Alpha-amylase & 47756 & 5.3 & 20 & $59 \%$ \\
\hline 57900682 & Uncharacterized protein At4g06744 & 44330 & 6.5 & 19 & $36 \%$ \\
\hline 55168101 & Cellulase & 57788 & 6.4 & 19 & $42 \%$ \\
\hline 34898314 & GDSL-like lipase/acylhydrolase & 40958 & 8.2 & 18 & $47 \%$ \\
\hline 20160767 & Xylanase inhibitor & 43787 & 9.2 & 15 & $43 \%$ \\
\hline
\end{tabular}

${ }^{\mathrm{a}} \mathrm{Gl}$ (GenBank identifier) number indicates the protein accession number in NCBI.

Table 2. Representative rice non-classical cell wall proteins that lack a signal peptide as predicted by SecretomeP 2.0

\begin{tabular}{|c|c|c|c|c|c|c|}
\hline $\mathrm{Gl}^{\mathrm{a}}$ & Function & $\begin{array}{c}\text { Molecular } \\
\text { mass }\end{array}$ & pl & $\begin{array}{l}\text { Sequence } \\
\text { count }\end{array}$ & $\begin{array}{l}\text { Sequence } \\
\text { coverage }\end{array}$ & NN-score ${ }^{b}$ \\
\hline 51963380 & Unknown protein & 67355 & 6.7 & 27 & 0.576 & 0.524 \\
\hline 50509692 & Beta-1,3-glucanase & 53753 & 6.1 & 26 & 0.585 & 0.725 \\
\hline 51964830 & Unknown protein & 67154 & 7.2 & 20 & 0.386 & 0.599 \\
\hline 22830913 & Endo-1,3-beta-glucanase & 67635 & 5.5 & 18 & 0.37 & 0.683 \\
\hline 460989 & Beta tubulin & 43002 & 4.9 & 14 & 0.386 & 0.55 \\
\hline 38345164 & Unknown protein & 71231 & 8.8 & 11 & 0.255 & 0.566 \\
\hline 50912401 & Aldehyde dehydrogenase & 45483 & 6.3 & 11 & 0.333 & 0.543 \\
\hline 50938789 & Early nodulin 8 like protein & 22215 & 8.2 & 9 & 0.47 & 0.582 \\
\hline 3023713 & Enolase & 47987 & 5.6 & 8 & 0.215 & 0.53 \\
\hline 38346903 & Unknown protein & 52786 & 8.3 & 8 & 0.176 & 0.503 \\
\hline 50510001 & Prohibitin & 31955 & 9.8 & 8 & 0.343 & 0.607 \\
\hline 51964530 & Unknown protein & 46830 & 8.2 & 8 & 0.208 & 0.702 \\
\hline 730456 & $40 S$ ribosomal protein $\mathrm{S} 19$ & 16387 & 10 & 7 & 0.507 & 0.703 \\
\hline 34893994 & $40 S$ ribosomal protein S5 & 22227 & 9.7 & 7 & 0.25 & 0.827 \\
\hline 38344200 & Unknown protein & 55227 & 7.9 & 7 & 0.153 & 0.539 \\
\hline 542153 & Translation initiation factor elF-4A & 46932 & 5.5 & 6 & 0.232 & 0.573 \\
\hline 37533060 & Unknown protein & 96740 & 5.8 & 6 & 0.085 & 0.589 \\
\hline 42408023 & Phosphoribosyl pyrophosphate synthetase & 36149 & 6.8 & 6 & 0.265 & 0.823 \\
\hline 50907169 & Unknown protein & 90986 & 6.5 & 6 & 0.129 & 0.587 \\
\hline 51854281 & Unknown protein & 90130 & 5.5 & 6 & 0.117 & 0.525 \\
\hline
\end{tabular}

${ }^{a} \mathrm{Gl}$ (GenBank identifier) number indicates the protein accession number in NCBI.

${ }^{b}$ Cutoff value of the NN-score for non-classical cell wall proteins is greater than 0.5 . 
Rice Cell Wall Proteome

Won Kyong Cho et al.

Table 3. GPI-anchored proteins isolated from the rice cell wall preparation identified by three prediction programs

\begin{tabular}{|c|c|c|c|c|c|c|c|}
\hline $\mathrm{Gl}^{\mathrm{a}}$ & Function $^{b}$ & Rice locus & Evalue & Length & $\begin{array}{l}\text { Molecular } \\
\text { mass }\end{array}$ & $\mathrm{pl}$ & Omega-site $^{c}$ \\
\hline 62733403 & Os3bglu8 - beta-glucosidase & LOC_Os03g49610.1 & 0 & 603 & 67245 & 7.4 & 573 \\
\hline 55733786 & $\begin{array}{l}\text { Glucan endo-1,3-beta-glucosidase-like } \\
\text { protein } 3\end{array}$ & LOC_Os05g43690.1 & $5.00 \mathrm{E}-52$ & 228 & 21760 & 5.7 & 204 \\
\hline 51964118 & $\begin{array}{l}\text { Glycerophosphoryl diester } \\
\text { phosphodiesterase family }\end{array}$ & LOC_Os02g37590.1 & 0 & 749 & 81084 & 6.1 & 723 \\
\hline 51963864 & Glucan endo-1,3-beta-glucosidase & LOC_Os02g04670.1 & 0 & 489 & 53375 & 5.5 & 459 \\
\hline 51243456 & $\begin{array}{l}\text { LysM domain-containing GPI-anchored } \\
\text { protein } 1\end{array}$ & LOC_Os06g10660.1 & 0 & 409 & 40488 & 4.9 & 387 \\
\hline 50943329 & $\begin{array}{l}\text { Plastocyanin-like domain containing } \\
\text { protein }\end{array}$ & LOC_Os08g17160.1 & $3.00 \mathrm{E}-69$ & 193 & 19274 & 8.3 & 169 \\
\hline 50941247 & Monocopper oxidase & LOC_Os08g05820.1 & 0 & 600 & 66229 & 6.8 & 576 \\
\hline 50939031 & X8 domain containing protein & LOC_Os07g40940.1 & $7.00 \mathrm{E}-43$ & 191 & 18902 & 5.7 & 167 \\
\hline 50932835 & X8 domain containing protein & LOC_Os05g50490.3 & $1.00 \mathrm{E}-136$ & 281 & 28222 & 6 & 255 \\
\hline 50919115 & Glucan endo-1,3-beta-glucosidase & LOC_Os03g57880.3 & 0 & 491 & 52783 & 5 & 467 \\
\hline 50918839 & X8 domain containing protein & LOC_Os03g54910.1 & $1.00 \mathrm{E}-68$ & 175 & 17825 & 4.8 & 149 \\
\hline 50912821 & $\begin{array}{l}\text { Eukaryotic aspartyl protease domain } \\
\text { containing protein }\end{array}$ & LOC_Os02g51540.1 & 0 & 520 & 56272 & 6 & 494 \\
\hline 50907029 & Pectinesterase & LOC_Os02g18650.1 & 0 & 554 & 58764 & 9.5 & 536 \\
\hline 38605955 & Fasciclin-like arabinogalactan protein & LOC_Os04g48490.1 & $1.00 \mathrm{E}-170$ & 431 & 44536 & 6.7 & 410 \\
\hline 37805880 & Retrotransposon protein & LOC_Os08g16810.1 & $8.00 \mathrm{E}-51$ & 130 & 13441 & 10.4 & 102 \\
\hline 37531036 & Thaumatin-like protein 1 & LOC_Os10g05600.1 & $1.00 \mathrm{E}-135$ & 389 & 38581 & 4.8 & 362 \\
\hline 34897712 & Monocopper oxidase & LOC_Os06g01490.1 & 0 & 593 & 65750 & 6.5 & 570 \\
\hline
\end{tabular}

${ }^{a} \mathrm{GI}$ (Gene Identifier) number indicates the protein accession number in NCBI.

${ }^{\mathrm{b}}$ Putative functions of $17 \mathrm{GPI}$-anchored proteins based on the annotation of the Rice Genome Annotation Project (http://rice.plantbiology.msu.edu/).

${ }^{\mathrm{C}} \mathrm{Omega-site}$ for GPI-anchored signal in protein sequences was predicted by the Big-PI program.

Table 4. A comparison between the classical cell wall proteins identified by four different cell wall proteome studies. Criterion for classical cell wall proteins is that they contain a signal peptide predicted by SignalP3.0

\begin{tabular}{|c|c|c|c|c|}
\hline Description & $\begin{array}{c}\text { Weakly bound } \\
\text { proteins }^{\mathrm{a}}\end{array}$ & $\begin{array}{l}\text { Purely secreted } \\
\text { proteins }^{\mathrm{b}}\end{array}$ & $\begin{array}{c}\text { Tightly bound } \\
\text { proteins }\left(\mathrm{CaCl}_{2}\right)^{\mathrm{c}}\end{array}$ & $\begin{array}{l}\text { Tightly bound } \\
\text { proteins (SDS) }\end{array}$ \\
\hline No. of classical cell wall proteins & 205 & 153 & 251 & 312 \\
\hline No. of proteins without a signal peptide & 1456 & 402 & 722 & 1157 \\
\hline No. of total proteins & 1705 & 555 & 973 & 1469 \\
\hline Ratio of classical cell wall proteins to total proteins & $14.6 \%$ & $27.6 \%$ & $25.8 \%$ & $21.2 \%$ \\
\hline
\end{tabular}

aStudy on weakly-bound rice cell wall proteome (Chen et al., 2009)

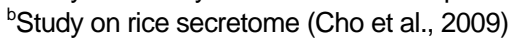

${ }^{\circ}$ Current study on tightly-bound rice cell wall proteome extracted by $\mathrm{CaCl}_{2}$

${ }^{d}$ Current study on tightly-bound rice cell wall proteome extracted by SDS

within the SDS-extracted fraction when compared to the 971 proteins extracted by $\mathrm{CaCl}_{2}$ (Fig. 2C). The combined total of all rice proteins identified in this study was 1999; 530 and 1028 proteins were unique and 441 proteins were common for the $\mathrm{CaCl}_{2}$ - and SDS-extracted fractions, respectively (Fig. $2 \mathrm{C})$.
Proteins predicted to contain a signal peptide

In general, protein targeting to the extracellular space requires an N-terminal signal peptide that mediates in the translocation of secreted proteins through the ER/Golgi pathway (Rabouille et al., 2012). The presence of a signal peptide in the $\mathrm{N}$-terminus of identified cell wall proteins was investigated using the SignalP 
$\boldsymbol{A}$

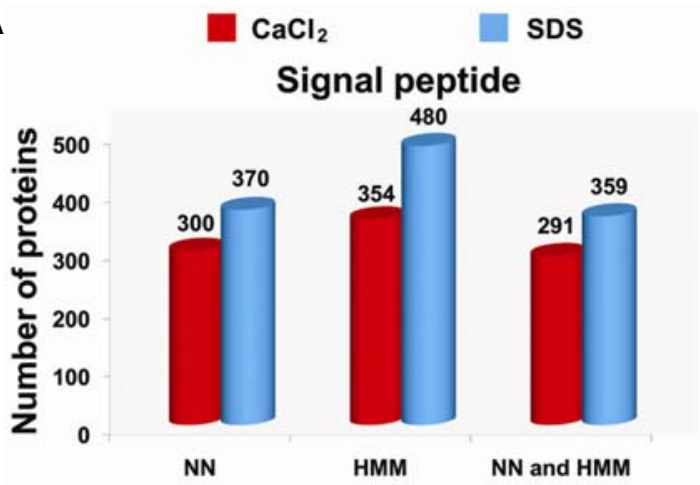

$\boldsymbol{B}$

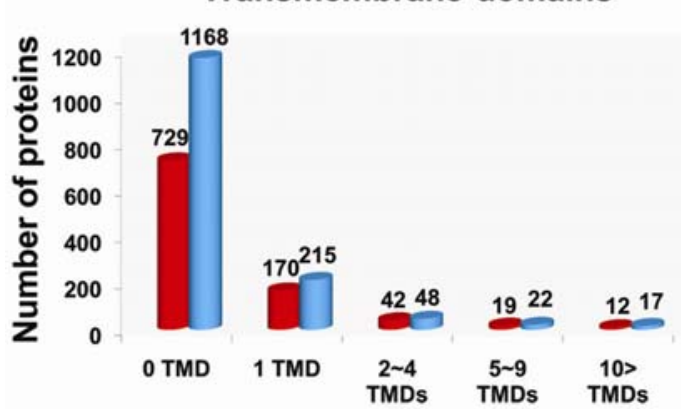

Fig. 3. Statistics of rice cell wall proteins containing a predicted signal peptide and transmembrane domains. (A) Number of proteins having a predicted signal peptide based on SignalP 3.0 using the NN and HMM algorithms. (B) Number of proteins having predicted transmembrane domains (TMDs) based on the TMHMM $\mathrm{V}$. 2.0 program.

3.0 algorithms, SignalP-NN and SignalP-HMM (Emanuelsson et al., 2007). Based on the NN program, some $300 \mathrm{CaCl}_{2}$ - and 370 SDS-extracted proteins were predicted to contain signal peptides (Fig. 3A). As compared to the NN algorithm, the number of secreted proteins predicted by the HMM method to have a signal peptide was slightly higher, being 354 and 480 from $\mathrm{CaCl}_{2}$ and SDS treatments, respectively (Fig. 3A). Finally, to ensure a low error rate, only rice proteins (458 unique proteins) containing a signal peptide predicted by both algorithms (291 and 359 from $\mathrm{CaCl}_{2}$ and SDS treatments) were categorized for further consideration to identify classical cell wall proteins (Emanuelsson et al., 2007).

\section{Identification of proteins containing predicted transmembrane helices}

Given the intimate association between the plant cell wall and the plasma membrane, it is technically difficult, if not impossible, to separate completely the proteins from these two cellular domains. Furthermore, PD are plant-specific intercellular organelles that are inserted within the matrix of the cell wall and contain both ER and plasma membrane components. Thus, it is likely that our cell wall proteome will include PD-localized plasma membrane and ER_proteins. To assess this situation, the TMHMM v. 2.0 program was used to identify candidate proteins containing transmembrane helices (Möller et al., 2001). As expected, 243 cell wall proteins were predicted to contain one or more transmembrane domains (Supplementary Table
S5). For example, $25 \%$ and $21 \%$ of the proteins within the $\mathrm{CaCl}_{2}$ and $\mathrm{SDS}$ extracted fractions, respectively, were predicted to be membrane proteins (Fig. 3B)

The number of transmembrane helices for any given cell wall protein was highly variable, ranging from one to 20 domains. For instance, there were $170 \mathrm{CaCl}_{2}$ and 215 SDS extracted proteins that contained a single transmembrane domain (Fig. $3 \mathrm{~B})$. Here, some 27 predicted receptor-like kinase proteins were identified that contained a single transmembrane domain (Supplementary Table S6). In contrast, two proteins, callose synthase 1 (LOC_Os03g03610.3) and embryogenesis transmembrane protein (LOC_Os06g18880.1), have 15 and 20 predicted transmembrane domains, respectively (Supplementary Table S6).

Identification of classical cell wall proteins based on bioinformatics

A further analysis of the signal peptide-containing cell wall proteins (Fig. $3 A$ ) identified 458 non-redundant proteins, which were predicted as a signal peptide-containing cell wall protein by both the NN and HMM algorithms (Supplementary Table S6). Among them, 66 were eliminated as they contained more than one predicted membrane domain. However, in other cases, the transmembrane domain within the $\mathrm{N}$-terminus was often predicted as a signal peptide because of the hydrophobic characteristics. Hence, when the predicted transmembrane helix overlapped with a predicted signal peptide, such proteins were regarded as classical cell wall or secreted proteins. Based on this criterion, predicted transmembrane domains in 178 proteins were classified as a signal peptide and these were included in the secreted protein category (Supplementary Table S6).

Proteins contained within the ER possess classical retention signals, such as an HDEL or KDEL sequence located at the Cterminus. Interestingly, we identified only two DnaK family proteins (LOC_Os05g35400.1 and LOC_Os02g02410.1) and a hydrolase (LOC_Os01g37960.1) that possessed ER retention motifs (Supplementary Table S6). This finding supports the notion that our extracted rice proteins are specifically enriched for cell wall proteins. After exclusion of 66 plasma membrane and 3 ER proteins, based on the above criteria, we identified some 389 classical rice cell wall proteins predicted to be secreted into the extracellular matrix, via a default secretory pathway (Table 1 and Supplementary Table S7).

\section{Prediction of non-classical secreted proteins}

In comparison to previous 2-DGE-based cell wall proteomics, the number of proteins lacking a signal peptide was quite high. Thus, the possibility existed that, of the remaining 1610 identified proteins, a significant number might well reflect cytosolic and membrane contaminants. However, some of these proteins may be secreted via a non-classical secretory pathway.

In order to remove proteins targeted to organelles, such as plastids and mitochondria, the TargetP 1.1 program was employed to screen the remaining rice proteins (Emanuelsson et al., 2007). Based on this analysis, 205 and 226 proteins were identified as likely being targeting to plastids and mitochondria, respectively (Fig. 4). We next used the SecretomeP program to identify potential non-classical secreted proteins (Bendtsen et al., 2004). Although this program was initially designed for mammalian cells, we assumed that secreted proteins in eukaryotic cells might well have common properties. In any event, using this approach 334 putative non-conventional secreted proteins were identified (Table 2, Fig. 4 and Supplementary Table S8A). The cell wall localization of such proteins was ex- 
Rice Cell Wall Proteome

Won Kyong Cho et al.

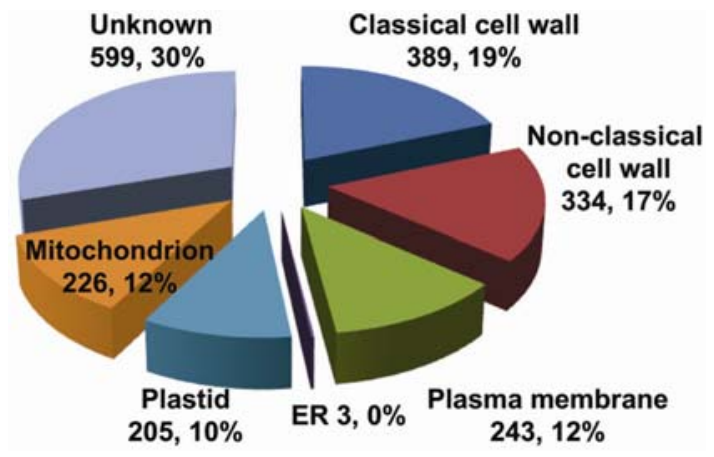

Fig. 4. Pie diagram illustrating the potential sub-cellular protein localization for the rice callus proteome. Classical cell wall proteins contain a signal peptide (predicted by both $\mathrm{NN}$ and HMM algorithms of SignalP 3.0), but lack transmembrane domains (predicted by the TMHMM v. 2.0 program). Plasma membrane proteins were predicted by the TMHMM v. 2.0 program. Proteins possessing both a predicted signal peptide and a transmembrane domain were scored as classical cell wall proteins. Plastid and mitochondrial proteins were predicted by the TargetP 1.1 program and considered as contaminated proteins. Non-classical cell wall proteins were predicted by the SecretomeP 2.0 program. Proteins containing an ER retention motif (KDEL or HEDL) at C-terminal region were identified as ER proteins.

perimentally validated by randomly picking up two proteins to be fused with fluorescent reporter green fluorescent protein (GFP) using tobacco leaf infiltration system. As shown in Supplementary Fig. S3, green fluorescent signals associated with LOC_Os02g 37710.1 belonging to lecithin cholesterol acyltransferase-like protein family, and LOC_Os01g71860.1 belonging to endo-1,3-beta-glucanase family were found not only in cytoplasm, but also in extracellular space as shown by plasmolysis. Collectively, we identified 389 classical cell wall proteins (19\%) and 334 putative non-classical (17\%) cell wall proteins, leaving 599 proteins $(30 \%)$ unassigned to any predicted subcellular localization (Fig. 4).

\section{Identification of GPl-anchored proteins}

In plants, many proteins can be anchored to the extracellular surface of the plasma membrane following glycosylphosphatidylinositol (GPI) posttranslational modification. In general, GPIanchored proteins have two highly conserved domains, composed of an N-terminal signal peptide and a C-terminal hydrophobic signal sequence, termed the omega site (Eisenhaber et al., 2003). This site is located between 20 and 30 residues upstream of the C-terminus. During posttranslational processing in the ER, the omega site in GPI-anchored proteins is cleaved and a glycolipid is then attached.

An earlier genome-wide analysis, using computational methods, identified some 198 and $180 \mathrm{GPI}$-anchored proteins in rice and Arabidopsis, respectively (Eisenhaber et al., 2003). To identify putative GPI-anchored proteins, we next used the PreGPI, Big-PI and GPI-SOM programs (Eisenhaber et al., 2003; Fankhauser and Mäser, 2005; Pierleoni et al., 2008). Among these programs, the Big-PI program employs experimental data, likely making it the more reliable method (Eisenhaber et al., 2003). The GPI-SOM and Pre-GPI programs predicted 62 and $73 \mathrm{GPI}$-anchored proteins, respectively, whereas the Big-PI identified only 20 such proteins (Fig. 5).

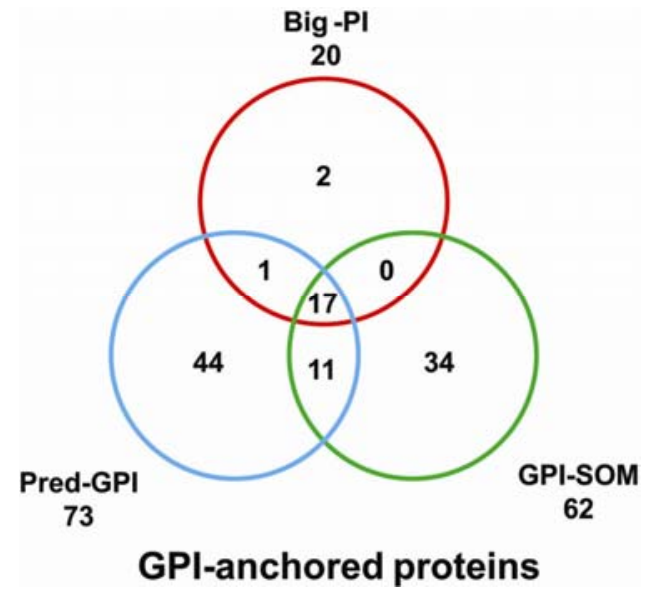

Fig. 5. Venn diagram illustrating GPI-anchored proteins predicted by the Big-PI, Pred-GPI, and GPI-SOM programs

As mentioned above, the presence of a signal peptide is a prerequisite for $\mathrm{GPI}$-anchoring. 18 of 20 proteins predicted by the Big-PI predictor program contained a signal peptide (Supplementary Table S6). However, only 66 of 73 and 52 of 62 proteins predicted by the Pred-GPI and GPI-SOM programs, respectively, had a signal peptide (Supplementary Table S6). Of the identified GPI-anchored proteins, the 17 proteins predicted by all three programs are likely to be GPI-anchored to the plasma membrane (Fig. 5). Here, three glucan endo-1,3-betaglucosidases, a LysM domain-containing protein, three X8 domain containing proteins, and a monocopper oxidase were identified as GPI-anchored proteins (Table 3). These GPIanchored proteins are included in the list of classical cell wall proteins, since extracellular domain of these proteins can be cleaved by diverse phosphatases (Brewis et al., 1994).

\section{Distribution of molecular mass and isoelectric points for} the rice cell wall proteome

The molecular mass distribution of the 1999 putative cell wall proteins was highly variable, ranging from 8 to $359 \mathrm{kDa}$, with the average being $60 \mathrm{kDa}$ (Supplementary Table S6). Due to the unbiased characteristics of MudPIT technology, the molecular mass of these proteins exhibited a normal distribution (Supplementary Fig. S1A). The molecular mass distribution of the 389 cell wall and 243 membrane proteins was also examined; profiles similar to that of the total proteome were obtained (Supplementary Figs. S1B and S1C).

The isoelectric points (pls) of proteins in the rice cell wall proteome ranged from 4.3 to 11.9 , with 7.5 being the average value (Supplementary Table S6). Here, only 49 and 34 proteins had values less than 5 and higher than 11, respectively (Supplementary Fig. S1D). The distribution patterns of the 1999 proteins and the 389 cell wall proteins were comparable, without any bias towards acidic or alkali proteins (Supplementary Figs. S1D and S1E). This result is similar to that of an earlier Arabidopsis cell wall proteome study (Bayer et al., 2006). Interestingly, as shown in Supplementary Fig. S1F, the 243 membrane proteins displayed a dissimilar pl pattern to that of the secreted proteins.

Functional characterization of the rice cell wall proteome To gain insights into the role of the proteins contained within the 

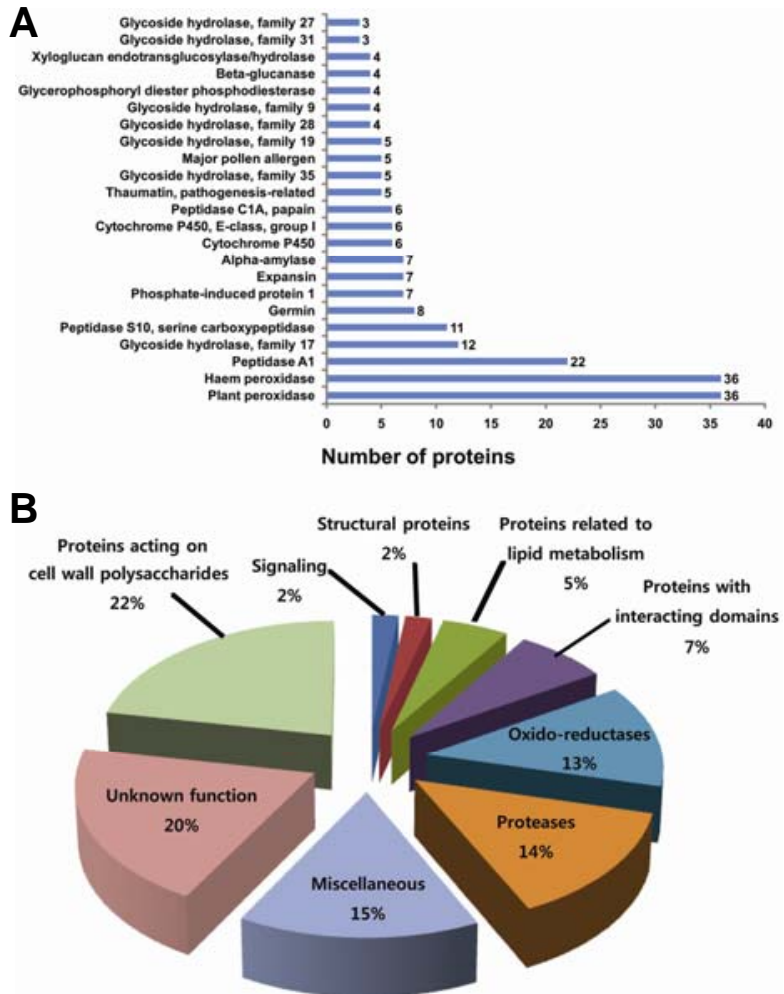

Fig. 6. Conserved domains and functional categories for the 389 classical rice cell wall proteins. (A) Distribution of the most frequently identified conserved domains based on the InterProScan database implemented in Blast2GO. Conserved domains with more than two proteins are displayed. (C) Functional categories identified based on the WallProtDB database (http://www.polebio.scsv.upstlse.fr/WallProtDB/).

rice cell wall proteome, the Blast2Go program was used to assign putative functions, based on gene ontology (GO) (Götz et al., 2008; Jensen and Bork, 2010). Using this approach, some 1200 proteins were annotated in two GO categories, namely biological processes and molecular functions. Based on biological processes, many of these proteins were predicted to be involved in a wide range of metabolic pathways (890 proteins), from response to various stimuli (455 proteins) to developmental processes (413 proteins) and gene expression (263 proteins) (Supplementary Fig. S2A). These findings are consistent with previous studies which have established that cell wall proteins participate in numerous metabolic processes and responses to environmental cues (Jamet et al., 2008). Similarly, based on molecular function, many proteins were assigned to binding (969 proteins), catalytic (842 proteins), hydrolase (414 proteins), transferase (214 proteins), structural (108 proteins) and kinase (106 proteins) activities (Supplementary Fig. S2B). To further analyze the functions likely associated with the 389 classical rice cell wall proteins, we next examined the conserved domains of each protein using the InterProScan database implemented in the Blast2Go program (Götz et al., 2008; Mulder and Apweiler, 2007). Proteins in the following families were found to be abundant: peroxidases (36), peptidase A1 (22) and glycoside hydrolases (36) (Fig. 6A). Protein families containing fewer members included the peptidase $\mathrm{S} 10 /$ serine

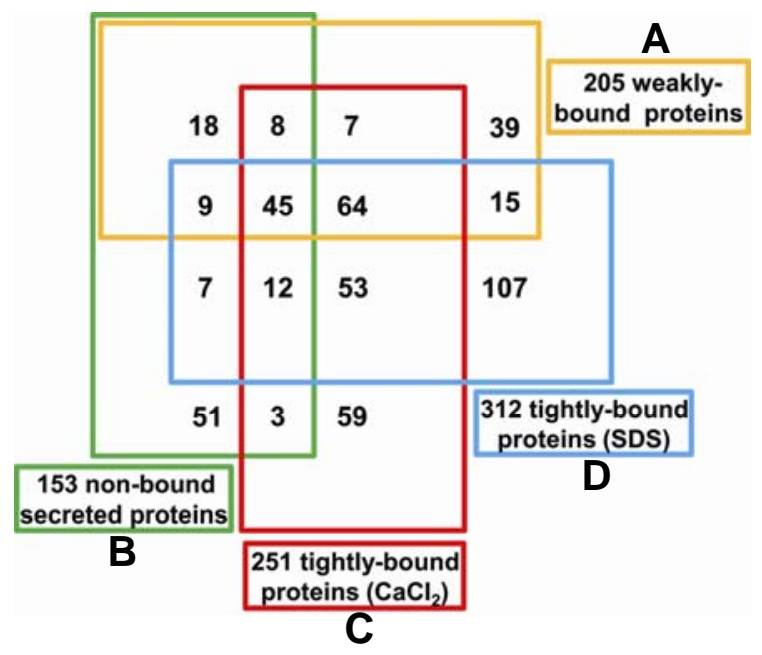

Fig. 7. Distribution of rice cell wall proteins identified by four methods. (A) Weakly-bound cell wall proteome (Chen et al., 2009). (B) Rice proteins identified by secretome analysis (Cho et al., 2009). (C) Tightly-bound cell wall proteins extracted by $\mathrm{CaCl}_{2}$ treatment. (D) Tightly-bound cell wall proteins extracted by SDS treatment.

carboxypeptidase (11), germin (8), phosphate-induced protein 1 (7), expansin (7) and alpha-amylase (7).

We next categorized these 389 conventional cell wall proteins into eight functional groups, according to the previous annotation of WallProtDB (http://www.polebio.scsv.ups-tlse.fr/ WallProtDB/). Here, some $80 \%$ of the identified proteins could be assigned into functional groups: among them were proteins acting on cell wall polysaccharides (22\%), proteases (14\%), oxido-reductases (13\%), but various miscellaneous proteins (15\%) were also present (Fig. 6B).

Of the identified 334 non-classical rice cell wall proteins, a large fraction (approx. 150 proteins) was assigned as being of unknown function. To further analyze this group, they were examined for conserved domains using the InterProScan database: a total of 793 redundant domains were identified. Domains for armadillo-type fold, RNA recognition motif, nucleotidebinding, F-box domain, protein kinase-like domain, glycoside hydrolase, $N A D(P)$-binding domain, and tubulin were frequently found (Supplementary Table S8B).

\section{Comparison of rice and Arabidopsis cell wall proteomes} To develop a comprehensive rice cell wall proteome database, we integrated data from our current and previous studies. For this purpose, we used only classical cell wall proteins that possess a signal peptide. As shown in Fig. 7, four independent rice cell wall proteomes have been established using rice callus cultured material. The first study used a non-destructive mannitol/ $\mathrm{CaCl}_{2}$ method to identify some 205 weakly-bound cell wall proteins (Chen et al., 2009). The second study focused on proteins secreted into the rice callus culture medium; here, 153 cell wall proteins were detected (Cho et al., 2009). The third and fourth studies used $\mathrm{CaCl}_{2}$ - and SDS-based protein extraction protocols; 251 and 312 tightly-bound cell wall proteins were extracted, respectively (current study).

Then, we established an expanded rice cell wall proteome database comprised of 496 classical secreted proteins (Supplementary Table S9). This rice database was next used to 


\section{Rice CWPs 244 Arabidopsis CWPs}

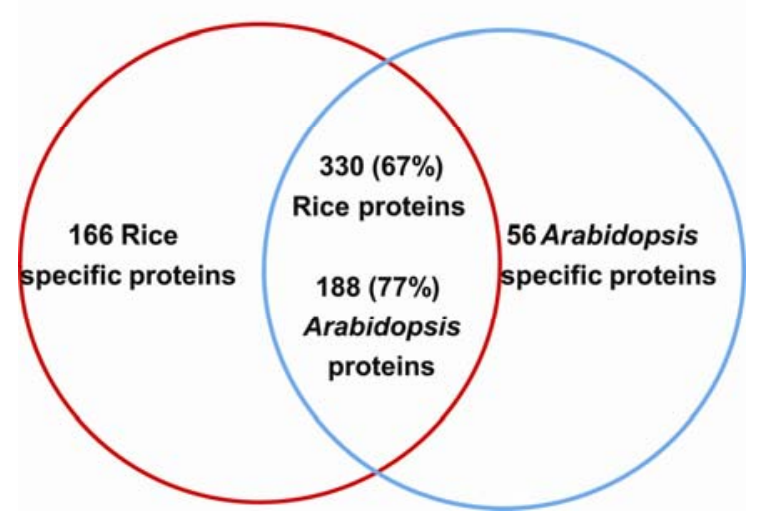

Fig. 8. Comparison of rice and Arabidopsis classical cell wall proteins. BLASTP was used to analyze 496 rice and 244 Arabidopsis cell wall proteins (CWPs; cutoff value of $1 \mathrm{E}-6$ ).

analyze the level of conservation with the current Arabidopsis cell wall proteome, containing some 244 conventional secreted proteins (Bayer et al., 2006). To this end, the BLASTP program was used with an 1E-6 cutoff value; here, 166 and 56 cell wall proteins were identified that appeared to be specific for rice and Arabidopsis, respectively (Fig. 8, Supplementary Tables S10A and $\mathrm{S} 10 \mathrm{~B})$. However, 330 rice $(67 \%)$ and 188 Arabidopsis $(77 \%)$ proteins were common to both proteomes, consistent with a high level of conservation between the cell wall proteomes of the monocots and eudicots (Fig. 8). Future functional analyses of these identified rice cell wall proteins will offer important insights into the roles they perform in wall chemistry, signaling and defense.

\section{DISCUSSION}

In the present study, a large scale proteomics experiment was performed to explore the nature of tightly-bound proteins present in the rice callus cell wall. To this end, we employed a combination of destructive methods, two protein extraction protocols and a MudPIT interrogation approach. Total 1999 proteins were identified by a combination of destructive methods (Fig. 2C). This total is relatively high as compared to 2DGE-based proteomics, in which around $54-300$ cell wall proteins have been identified (Jung et al., 2008; Kim et al., 2013; Zhou et al., 2011), indicating that this current study led to the identification of a significant number of additional plant cell wallassociated proteins.

In our current rice cell wall proteome, we identified 389 classical cell wall proteins possessing a conventional signal peptide, as well as 334 putative non-classical cell wall proteins that lacked such signal peptides. Approximately $80 \%$ of the classical cell wall proteins have functions related to cell wall polysaccharide chemistry, as well as to protease and oxido-reductase activities; however, some $40 \%$ of the identified non-classical cell wall proteins have unknown functions (Supplementary Tables S7 and S8A) and two candidate proteins LOC_Os02g 37710.1 and LOC_Os01g71860.1 have been experimentally validated for their secretion into extracellular space (Supplementary Fig. S3). This suggests that these non-classical proteins, which utilize unconventional export mechanisms, are likely to repre- sent important components of the extracellular matrix. To advance plant cell wall biology, it will be important to unraveling the molecular mechanisms that evolved to mediate unconventional protein secretion. In addition, it is important to note that a number of proteins identified in this study are homologous to known non-classical secreted proteins in other organisms, including bacteria, yeast, and mammals for which experimental evidence exists. Examples are annexin, enolase and elongation factor (Edwards et al., 1999; Marcilla et al., 2012; Marques et al., 1998). One such protein, elongation factor $1 \alpha$ that lacks a signal peptide was isolated from tobacco and has been shown to localize to the cell wall by immunogold localization (Zhu et al., 1994). In addition, GAPDH is another known non-classical cell wall protein in bacteria and yeast (Eichenbaum et al., 1996; Gozalbo et al., 1998). The GAPDH domain containing protein (LOC Os04g40950.1) identified in our study was assigned as an unknown protein without predicted localization. Regardless of proteins that are secreted, via either the classical or nonconventional secretory pathway, it is necessary to stress that other proteins identified in the rice cell wall proteome could well function in unknown biological processes by interacting with various components of the cell wall. Molecular methods will be needed to probe the cell wall localization of these proteins (Groover et al., 2003).

In conclusion, we have analyzed the tightly-bound cell wall proteins in rice calli using a combination of destructive methods. This sensitive and relatively unbiased approach identified a range of proteins involved in metabolic processes and responses to environmental cues. A comparative analysis of the Arabidopsis cell wall proteome and comprehensive rice cell wall proteome generated by combining our current and previous studies (Chen et al., 2009; Cho et al., 2009), suggests a predominant conservation between monocot and eudicot cell wall proteins. This rice cell wall proteome dataset could increase information on cell wall proteins, thus it will act as a valuable resource for further functional analysis of cell wall proteins.

Note: Supplementary information is available on the Molecules and Cells website (www.molcells.org).

\section{ACKNOWLEDGMENTS}

This work was supported by Basic Science Research Program (NRF-2013R1A1A2007230) through the National Research Foundation of Korea funded by the Ministry of Education, and funded by the Next-Generation BioGreen 21 Program (SSAC, grant PJ01137901), Rural Development Administration, Republic of Korea. DK was supported by Brain Korea 21 Plus program (BK21+).

\section{REFERENCES}

Altschul, S.F., Madden, T.L., Schäffer, A.A., Zhang, J., Zhang, Z., Miller, W., and Lipman, D.J. (1997). Gapped BLAST and PSIBLAST: a new generation of protein database search programs. Nucleic Acids Res. 25, 3389-3402.

Baluska, F., Hlavacka, A., Volkmann, D., and Menzel, D. (2004). Getting connected: actin-based cell-to-cell channels in plants and animals. Trends Cell Biol. 14, 404-408.

Bayer, E.M., Bottrill, A.R., Walshaw, J., Vigouroux, M., Naldrett, M.J., Thomas, C.L., and Maule, A.J. (2006). Arabidopsis cell wall proteome defined using multidimensional protein identification technology. Proteomics 6, 301-311.

Bendtsen, J.D., Jensen, L.J., Blom, N., Von Heijne, G., and Brunak, S. (2004). Feature-based prediction of non-classical and leaderless protein secretion. Protein Eng. Des. Sel. 17, 349-356.

Bhushan, D., Pandey, A., Chattopadhyay, A., Choudhary, M.K., 
Chakraborty, S., Datta, A., and Chakraborty, N. (2006). Extracellular matrix proteome of chickpea (Cicer arietinum L.) illustrates pathway abundance, novel protein functions and evolutionary perspect. J. Proteome Res. 5, 1711-1720.

Borderies, G., Jamet, E., Lafitte, C., Rossignol, M., Jauneau, A., Boudart, G., Monsarrat, B., Esquerré-Tugayé, M.T., Boudet, A., and Pont-Lezica, R. (2003). Proteomics of loosely bound cell wall proteins of Arabidopsis thaliana cell suspension cultures: a critical analysis. Electrophoresis 24, 3421-3432.

Brewis, I.A., Turner, A.J., and Hooper, N.M. (1994). Activation of the glycosyl-phosphatidylinositol-anchored membrane dipeptidase upon release from pig kidney membranes by phospholipase $\mathrm{C}$. Biochem. J. 303, 633-638.

Charmont, S., Jamet, E., Pont-Lezica, R., and Canut, H. (2005). Proteomic analysis of secreted proteins from Arabidopsis thaliana seedlings: improved recovery following removal of phenolic compounds. Phytochemistry 66, 453-461.

Chen, X.Y., Kim, S.T., Cho, W.K., Rim, Y., Kim, S., Kim, S.W., Kang, K.Y., Park, Z.Y., and Kim, J.Y. (2009). Proteomics of weakly bound cell wall proteins in rice calli. J. Plant Physiol. 166, 675-685.

Chivasa, S., Ndimba, B.K., Simon, W.J., Robertson, D., Yu, X.L., Knox, J.P., Bolwell, P., and Slabas, A.R. (2002). Proteomic analysis of the Arabidopsis thaliana cell wall. Electrophoresis 23, 1754-1765

Cho, W.K., Chen, X.Y., Chu, H., Rim, Y., Kim, S., Kim, S.T., Kim, S.W., Park, Z.Y., and Kim, J.Y. (2009). Proteomic analysis of the secretome of rice calli. Physiol. Plant. 135, 331-341.

Cui, S., Huang, F., Wang, J., Ma, X., Cheng, Y., and Liu, J. (2005). A proteomic analysis of cold stress responses in rice seedlings. Proteomics 5, 3162-3172.

Curtis, M.D., and Grossniklaus, U. (2003). A gateway cloning vector set for high-throughput functional analysis of genes in planta. Plant Physiol. 133, 462-469.

Dahal, D., Pich, A., Braun, H.P., and Wydra, K. (2010). Analysis of cell wall proteins regulated in stem of susceptible and resistant tomato species after inoculation with Ralstonia solanacearum: a proteomic approach. Plant Mol. Biol. 73, 643-658.

Denecke, J., De Rycke, R., and Botterman, J. (1992). Plant and mammalian sorting signals for protein retention in the endoplasmic reticulum contain a conserved epitope. EMBO J. 11, 2345-2355.

Eisenhaber, B., Wildpaner, M., Schultz, C.J., Borner, G.H., Dupree, P., and Eisenhaber, F. (2003). Glycosylphosphatidylinositol lipid anchoring of plant proteins. Sensitive prediction from sequenceand genome-wide studies for Arabidopsis and rice. Plant Physiol. 133, 1691-1701.

Edwards, S.R., Braley, R., and Chaffin, W.L. (1999). Enolase is present in the cell wall of Saccharomyces cerevisiae. FEMS Microbiol. Lett. 177, 211-216.

Eichenbaum, Z., Green, B.D., and Scott, J.R. (1996). Iron starvation causes release from the group A streptococcus of the ADPribosylating protein called plasmin receptor or surface glyceraldehyde-3-phosphate-dehydrogenase. Infect. Immun. 64, 1956-1960.

Emanuelsson, O., Brunak, S., von Heijne, G., and Nielsen, $\mathrm{H}$. (2007). Locating proteins in the cell using TargetP, SignalP and related tools. Nat. Protoc. 2, 953-971.

Fankhauser, N., and Mäser, P. (2005). Identification of GPI anchor attachment signals by a Kohonen self-organizing map. Bioinformatics 21, 1846-1852

Feiz, L., Irshad, M., Pont-Lezica, R.F., Canut, H., and Jamet, E. (2006). Evaluation of cell wall preparations for proteomics: a new procedure for purifying cell walls from Arabidopsis hypocotyls. Plant Methods 2, 10

Ge, C., Wan, D., Wang, Z., Ding, Y., Wang, Y., Shang, Q., Ma, F., and Luo, S. (2008). A proteomic analysis of rice seedlings responding to 1,2,4-trichlorobenzene stress. J. Environ. Sci. (China) 20, 309-319.

Götz, S., García-Gómez, J.M., Terol, J., Williams, T.D., Nagaraj, S.H., Nueda, M.J., Robles, M., Talón, M., Dopazo, J., and Conesa, A. (2008). High-throughput functional annotation and data mining with the Blast2GO suite. Nucleic Acids Res. 36, 3420-3435.

Gozalbo, D., Gil-Navarro, I., Azorín, I., Renau-Piqueras, J., J.P., and Gil, M.L. (1998). The cell wall-associated glyceralde- hyde-3-phosphate dehydrogenase of Candida albicans is also a fibronectin and laminin binding protein. Infect. Immun. 66, 20522059.

Groover, A.T., Fontana, J.R., Arroyo, J.M., Yordan, C., McCombie, W.R., and Martienssen, R.A. (2003). Secretion trap tagging of secreted and membrane-spanning proteins using Arabidopsis gene traps. Plant Physiol. 132, 698-708.

Hiei, Y., Ohta, S., Komari, T., and Kumashiro, T. (1994). Efficient transformation of rice (Oryza sativa L.) mediated by Agrobacterium and sequence analysis of the boundaries of the T-DNA. Plant J. 6, 271-282.

Jamet, E., Albenne, C., Boudart, G., Irshad, M., Canut, H., and Pont-Lezica, R. (2008). Recent advances in plant cell wall proteomics. Proteomics 8, 893-908.

Jensen, L.J., and Bork, P. (2010). Ontologies in quantitative biology: a basis for comparison, integration, and discovery. PLoS Biol. 8 , e1000374.

Jung, Y.H., Jeong, S.H., Kim, S.H., Singh, R., Lee, J.E., Cho, Y.S., Agrawal, G.K., Rakwal, R., and Jwa, N.S. (2008). Systematic secretome analyses of rice leaf and seed callus suspensioncultured cells: workflow development and establishment of highdensity two-dimensional gel reference maps. J. Proteome Res. 7, 5187-5210.

Keegstra, K. (2010). Plant cell walls. Plant Physiol. 154, 483-486.

Kim, S.T., Kang, Y.H., Wang, Y., Wu, J., Park, Z.Y., Rakwal, R., Agrawal, G.K., Lee, S.Y., and Kang, K.Y. (2009). Secretome analysis of differentially induced proteins in rice suspensioncultured cells triggered by rice blast fungus and elicitor. Proteomics 9, 1302-1313.

Kim, S.G., Wang, Y., Lee, K.H., Park, Z.Y., Park, J., Wu, J., Kwon, S.J., Lee, Y.H., Agrawal, G.K., Rakwal, R., et al. (2013). Indepth insight into in vivo apoplastic secretome of riceMagnaporthe oryzae interaction. J. Proteomics 78, 58-71.

Komatsu, S., Kobayashi, Y., Nishizawa, K., Nanjo, Y., and Furukawa, K. (2010). Comparative proteomics analysis of differentially expressed proteins in soybean cell wall during flooding stress. Amino Acids 39, 1435-1349.

Kong, F.J., Oyanagi, A., and Komatsu, S. (2010). Cell wall proteome of wheat roots under flooding stress using gel-based and LC MS/MS-based proteomics approaches. Biochim. Biophys. Acta 1804, 124-136.

Marcilla, A., Trelis, M., Cortés, A., Sotillo, J., Cantalapiedra, F., Minguez, M.T., Valero, M.L., Sánchez del Pino, M.M., MuñozAntoli, C., Toledo, R., et al. (2012). Extracellular vesicles from parasitic helminths contain specific excretory/secretory proteins and are internalized in intestinal host cells. PLoS One 7, e45974.

Marques, M.A., Chitale, S., Brennan, P.J., and Pessolani, M.C. (1998). Mapping and identification of the major cell wallassociated components of Mycobacterium leprae. Infect. Immun 66, 2625-2631.

Millar, D.J., Whitelegge, J.P., Bindschedler, L.V., Rayon, C., Boudet, A.M., Rossignol, M., Borderies, G., and Bolwell, G.P. (2009). The cell wall and secretory proteome of a tobacco cell line synthesising secondary wall. Proteomics 9, 2355-2372.

Möller, S., Croning, M.D., and Apweiler, R. (2001). Evaluation of methods for the prediction of membrane spanning regions. Bioinformatics 17, 646-653.

Mulder, N., and Apweiler, R. (2007). InterPro and InterProScan: tools for protein sequence classification and comparison. Methods Mol. Biol. 396, 59-70.

Ndimba, B.K., Chivasa, S., Hamilton, J.M., Simon, W.J., and Slabas, A.R. (2003). Proteomic analysis of changes in the extracellular matrix of Arabidopsis cell suspension cultures induced by fungal elicitors. Proteomics 3, 1047-1059.

Ouyang, S., Zhu, W., Hamilton, J., Lin, H., Campbell, M., Childs, K., Thibaud-Nissen, F., Malek, R.L., Lee, Y., Zheng, L., et al. (2007) The TIGR Rice Genome Annotation Resource: improvements and new features. Nucleic Acids Res. 35, D883-D887.

Pandey, A., Rajamani, U., Verma, J., Subba, P., Chakraborty, N., Datta, A., Chakraborty, S., and Chakraborty, N. (2010). Identification of extracellular matrix proteins of rice (Oryza sativa L.) involved in dehydration-responsive network: a proteomic approach. J. Proteome Res. 9, 3443-3464.

Pettolino, F.A., Walsh, C., Fincher, G.B., and Bacic, A. (2012). Determining the polysaccharide composition of plant cell walls. Nat. Protoc. 7, 1590-1607. 
Pierleoni, A., Martelli, P.L., and Casadio, R. (2008). PredGPI: a GPI-anchor predictor. BMC Bioinformatics 9, 392.

Rabouille, C., Malhotra, V., and Nickel, W. (2012). Diversity in unconventional protein secretion. J. Cell Sci. 125, 5251-5255.

Robertson, D., Mitchell, G.P., Gilroy, J.S., Gerrish, C., Bolwell, G.P., and Slabas, A.R. (1997). Differential extraction and protein sequencing reveals major differences in patterns of primary cell wall proteins from plants. J. Biol. Chem. 272, 15841-15848.

Rose, J.K., and Lee, S.J. (2010). Straying off the highway: trafficking of secreted plant proteins and complexity in the plant cell wall proteome. Plant Physiol. 153, 433-436.

Tan, L., Eberhard, S., Pattathil, S., Warder, C., Glushka, J., Yuan, C., Hao, Z., Zhu, X., Avci, U., Miller, J.S., et al. (2013). An Arabidopsis cell wall proteoglycan consists of pectin and arabinoxylan covalently linked to an arabinogalactan protein. Plant Cell 25, 270-287.

Watson, B.S., Lei, Z., Dixon, R.A., and Sumner, L.W. (2004). Proteomics of Medicago sativa cell walls. Phytochemistry 65, 17091720.

Yan, J.X., Wait, R., Berkelman, T., Harry, R.A., Westbrook, J.A., Wheeler, C.H., and Dunn, M.J. (2000). A modified silver staining protocol for visualization of proteins compatible with matrixassisted laser desorption/ionization and electrospray ionizationmass spectrometry. Electrophoresis 21, 3666-3672.

Yang, J.L., Zhu, X.F., Peng, Y.X., Zheng, C., Li, G.X., Liu, Y., Shi, Y.Z., and Zheng, S.J. (2011). Cell wall hemicellulose contributes significantly to aluminum adsorption and root growth in Arabidopsis. Plant Physiol. 155, 1885-1892.

Zhu, J.K., Damsz, B., Kononowicz, A.K., Bressan, R.A., and Hasegawa, P.M. (1994). A higher plant extracellular vitronectin-like adhesion protein is related to the translational elongation factor1 alpha. Plant Cell 6, 393-404.

Zhu, J., Alvarez, S., Marsh, E.L., Lenoble, M.E., Cho, I.J., Sivaguru, M., Chen, S., Nguyen, H.T., Wu, Y., Schachtman, D.P., et al. (2007). Cell wall proteome in the maize primary root elongation zone. II. Region-specific changes in water soluble and lightly ionically bound proteins under water deficit. Plant Physiol. 145, 1533-1548

Zhou, L., Bokhari, S.A., Dong, C.J., and Liu, J.Y. (2011). Comparative proteomics analysis of the root apoplasts of rice seedlings in response to hydrogen peroxide. PLoS One 6, e16723. 